\title{
Pelatihan Soft Skills Dan Pendampingan Siswa-Siswi SMK Di Kota Bogor Untuk Persiapan Memasuki Dunia Kerja
}

\author{
Ade Tuti Turistiati ${ }^{a, 1}$, Hafizh Faikar Agung Ramadhan ${ }^{\text {b,2 }}$ \\ ${ }^{\text {a }}$ Program Studi Manajemen Komunikasi \\ ${ }^{\mathrm{b}}$ Fakultas Ilmu Sosial dan Manajemen, Institut STIAMI \\ ${ }^{1}$ turistiati@stiami.ac.id ; ${ }^{2}$ insanetheory1212@gmail.com
}

ARTICLE INFO

Keywords

soft skills

communication skills

confidence

work environment

\section{ABSTRACT}

Graduates of Vocational High School (SMK) are prepared to work in public/private sectors, or work independently as entrepreneurs. The students are given hard skills based on their chosen majors and soft skills. However, the needs for soft skills are often less considered. This soft skills training program and mentoring for students of SMK in Bogor city aims to make students understand the importance of soft skills. The students are expected to practice applying/using soft skills that support them in finding/creating jobs opportunities; write application letters; write interesting, informative, and effective Curriculum Vitae (CV). They are also expected to be self-confident to face a job interview. This program was followed by the 3rd graders of SMKN 1 and representatives of vocational school students in Bogor city, leaders and teachers of SMKN 1 Bogor. The training was divided into 2 batches; each batch consisted of 75 participants. After training and practicing, students were given the opportunity to consult directly (face to face) with facilitators, and seek for information and guidance through WhatsApp facilities and e-mails. The result of training and mentoring shows that the students understand the importance of soft skills such as communication skills, self-confidence, respect, openmindedness, and honesty in a working environment and daily life.

\section{PENDAHULUAN}

Sekolah Menengah Kejuruan atau SMK adalah salah satu jenjang pendidikan menengah dengan kekhususan mempersiapkan lulusannya untuk siap bekerja. Menurut Undang-Undang Sistem Pendidikan Nasional No. 20 Tahun 2003, pasal 3 mengenai tujuan pendidikan nasional dan penjelasan pasal 15 disebutkan bahwa pendidikan kejuruan merupakan pendidikan menengah yang mempersiapkan peserta didik terutama untuk bekerja di bidang tertentu. ("Undang-Undang Republik Indonesia No. 20 Tahun 2003 tentang Sistem Pendidikan Nasional,” 2016)

Berdasarkan uraian di atas, SMK sebagai sub-sistim pendidikan nasional seharusnya mengutamakan mempersiapkan peserta didiknya untuk mampu memilih karir, memasuki lapangan kerja, berkompetisi, dan mengembangkan dirinya dengan sukses di lapangan kerja yang cepat berubah dan berkembang. Perubahan dan perkembangan dunia kerja tersebut menuntut lulusan SMK mempunyai hard skills dan soft skills yang memenuhi tuntutan pekerjaan.

SMK Negeri 1 Bogor adalah salah satu sekolah menengah kejuruan di wilayah Kota Bogor yang berlokasi di jalan Heulang No.6 Kelurahan Tanah Sareal Kota Bogor. SMK Negeri 1 Bogor mempunyai tanggung jawab yang besar dalam menyiapkan sumber daya manusia yang tangguh sehingga mampu hidup selaras didalam perubahan teknologi. SMK Negeri 1 ini setiap tahun memiliki sekitar 1.300 siswa yang tersebar di 5 (lima) paket keahlian, yaitu Akuntansi, Administrasi Perkantoran, Pemasaran, Multimedia, dan Usaha Perjalanan Wisata.

Secara teknis (hard skills) para guru SMK Negeri 1 Bogor telah mempersiapkan lulusannya untuk dapat memasuki dunia kerja. Lulusan SMK Negeri 1 Bogor tergantung jurusan yang 
dipilihnya, mendapatkan mata pelajaran yang dibutuhkan baik secara teoretis maupun praktis. Selain itu, sebelum lulus para siswa melaksanakan magang di suatu perusahaan atau institusi. Namun, kenyataannya lulusan SMK termasuk SMKN 1 Bogor harus berkompetisi dengan lulusan perguruan tinggi program diploma bahkan sarjana untuk mendapatkan pekerjaan. Kondisi tersebut membuat mayoritas lulusan SMK merasa kurang percaya diri dan khawatir tidak dapat memasuki dunia kerja.

Berdasarkan kondisi tersebut di atas Kepala Sekolah SMKN 1 dan panitia serta ketua pelaksana kegiatan berinisiasi untuk mengadakan kegiatan berupa pelatihan. Pelatihan ini diikuti oleh siswa SMKN 1 kelas 3 dan perwakilan SMK-SMK di kota Bogor untuk mendapatkan pembekalan berupa motivasi dan pemahaman tentang soft skills (soft competency) untuk persiapan memasuki dunia kerja.

\section{MASALAH}

Masalah yang dihadapi oleh siswa SMK kelas 3 yang akan lulus dan memasuki dunia kerja adalah adanya persaingan dengan lulusan perguruan tinggi program diploma bahkan sarjana untuk mendapatkan pekerjaan. Kondisi tersebut membuat lulusan SMK kurang percaya diri dan khawatir tidak dapat memasuki dunia kerja. Berdasarkan masalah tersebut, pelatihan soft skills dan pendampingan sisma SMK di kota Bogor merupakan salah satu upaya untuk memberikan pemahaman sekaligus keterampilan bagi mereka agar mempunyai soft skills yang dibutuhkan sebelum dan ketika mereka bekerja.

\section{METODE PELAKSANAAN KEGIATAN}

Metoda pelaksanaan dari kegiatan pelatihan dan pendampingan tentang soft skills ini dibagi dalam beberapa tahap sebagai berikut:

a) Persiapan

Persiapan yang dilakukan melibatkan komunikasi intensif dengan penyelenggara kegiatan yaitu SMKN 1 Bogor melalui Wakil Kepala Sekolah-nya. Komunikasi dilaksanakan melalui telepon, media WhatsApp, e-mail, dan pertemuan tatap muka. Persiapan dilakukan menyangkut jadwal, peserta, undangan, konten pelatihan, metode/strategi pelatihan, tempat, sarana dan prasarana, rencana tindak lanjut (pendampingan dan konsultasi), dan lain-lain.

b) Pelaksanaan

Peserta kegiatan pelatihan dan konsultasi dibagi dalam 2 batch dengan masing-masing batch terdiri dari 75 orang peserta. Batch pertama diadakan pada tanggal 22 Oktober dan batch kedua tanggal 29 Oktober 2016. Pertemuan untuk setiap kelompok dilaksanakan selama 4 jam dari jam 08:00-12:00. Untuk konsultasi lebih lanjut, pelaksana kegiatan menyediakan waktu pada pukul 13:00-15:30. Selain itu peserta dapat mengirimkan pesan melalui WhatsApp, e-mail, atau menghubungi fasilitator langsung melalui telepon.

c) Evaluasi

Evaluasi program kegiatan secara keseluruhan dilaksanakan setelah acara pelatihan berlangsung dengan menyebarkan angket atau daftar pertanyaan. Angket dikumpulkan pada hari yang sama. Kemudian panitia mereview dan membuat rekomendasi berdasarkan hasil angket dan saran yang diberikan oleh para peserta. Hasil evaluasi disampaikan secara lisan oleh ketua panitia pada pelaksana kegiatan.

\section{HASIL DAN PEMBAHASAN}

\subsection{Perubahan Mind Set dan Motivasi}

Fasilitator dibantu asisten melakukan ice breaking yang interaktif sebelum masuk pada sesi merubah mind set dan memotivasi peserta. Siswa SMK harus mempunyai mind set bahwa mereka bertanggung jawab atas keberhasilan hidup mereka termasuk kesuksesan mereka dalam mendapatkan pekerjaan. Pihak sekolah dalam hal ini SMK memfasilitasi dengan memberikan 
program pendidikan disertai sarana dan prasana serta SDM (para guru) yang kompeten di bidangnya.

Fasilitator menggunakan NLP untuk merubah mind set dan memotivasi para peserta. NLP atau Neuro Linguistics Program dipilih sebagai metode untuk sesi motivasi karena relatif mudah dipahami dan dapat diaplikasikan dalam kehidupan sehari-hari.

"NLP adalah sebuah metodologi berdasarkan asumsi bahwa semua pemikiran dan tindakan mempunyai struktur dan struktur tersebut bisa dipelajari, dimodel, diajarkan, dan diubah atau diprogram kembali" (Nikolay, 2014)

NLP dapat digambarkan sebagai berikut:

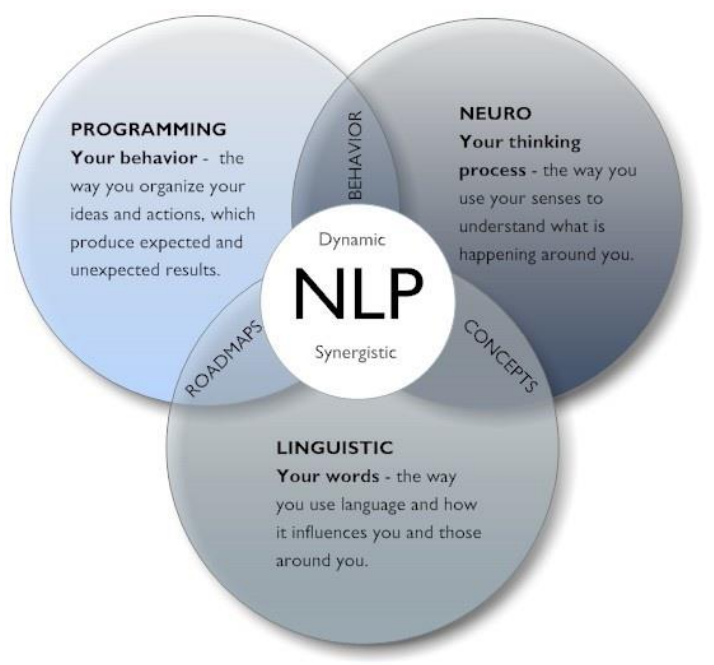

Gambar 1.1 Neuro Linguistics Programming (Sun, 2016)

Fasilitator menjelaskan kepada para peserta mengenai manfaat NLP berdasarkan penelitian yang dilakukan oleh Carey dan Millrood. Hal ini disampaikan agar peserta memahami dan percaya manfaat NLP.

Carey mengadakan penelitian dengan mengambil studi kasus terhadap 24 guru di Reading, Inggris sebelum dan sesudah mereka mengikuti pelatihan metode NLP. Hasilnya terdapat dampak signifikan baik terhadap guru-guru yang bersangkutan maupun terhadap siswa mereka. Dengan menerapkan NLP dalam mengajar dan mendidik siswa di sekolah, terjadi hubungan baik antara guru dengan siswa, saling memahami, komunikasi yang efektif, siswa belajar lebih fokus dan menyenangkan.(Carey, John; Churces, 2010)

Millrood dalam rangkaian penelitiannya mengadakan workshop bagi guru untuk mengetahui pengaruh NLP dalam pembelajaran bahasa Inggris terhadap siswanya. Kesimpulannya bahwa NLP membantu meningkatkan kemampuan siswa dalam memahami reading comprehension dan membantu mengorganisir pikiran, perasaan, ucapan dan perilaku dengan cara lebih baik. Para guru, perencana kurikulum, dan pembuat keputusan dapat mendesain instruksi program yang cocok dan tepat bagi siswa sesuai dengan tingkat pendidikan mereka.(Millrood, 2004)

Berdasarkan hasil penelitian di atas, metode NLP dapat digunakan sebagai alat untuk melakukan perubahan, diantaranya perubahan mind set. Perubahan mind set ini penting agar para siswa SMK berorientasi ke depan dan mempunyai semangat tinggi untuk bersaing dan berjuang meningkatkan kemampuan diri baik dalam teknis (hard skills) maupun soft skills.

Fasilitator memotivasi para peserta dengan menyampaikan 7 kunci sukses yang dijelaskan secara komprehensif dan interaktif. Ke 7 kunci sukses adalah sebagai berikut:

1) Saya. Saya yang menentukan hasil yang dicapai. Keberhasilan di tangan saya sendiri.

2) Outcome-Hasil. Tahu/dapat membayangkan hasil akhir apa yang kita inginkan. 
3) Fleksibilitas-Fokus pada manfaat. Jika apa yang kita lakukan belum memberikan apa yang kita inginkan, ubahlah apa yang kita lakukan.

4) Perjuangan TIDAK pernah sia-sia. Selalu ada pelajaran dan hikmah dibalik semua kejadian

5) Tuhan memberikan segala sesutu pada kita tepat pada waktunya menurutNya.

6) Doa Orang Tua

7) Tak seorang pun atau apapun yang dapat menyakiti kita dan membuat kita lemah kecuali kita mengizinkannya.

\subsection{Hard Competency (Hard Skills) dan Soft Competency (Soft Skills)}

Menurut Kamus Kompetensi yang dikeluarkan oleh Harvard University, kompetensi merupakan sesuatu dalam diri seseorang yang harus ditampilkan agar pekerjaan, peran, fungsi, atau tugas menjadi efektif. Hal tersebut termasuk didalamnya perilaku yang sesuai dengan tuntutan pekerjaan, motivasi, serta pengetahuan teknis/keterampilan teknis.

Kompetensi terdiri dari hard competency (hard skills) dan soft competency (soft skills). Hard skills mudah diamati dan dikembangkan, biasanya berupa keterampilan teknis atau pengetahuan. Misalnya : keterampilan menjahit pakaian, kemampuan mengoperasikan komputer dengan menggunakan program tertentu, kemampuan mengoperasikan mesin, kemampuan mengendarai mobil, dan lain-lain. Soft skills merupakan sesuatu yang relatif sulit untuk diamati dan butuh waktu untuk mengembangkannya. Soft skills di antaranya motivasi, watak, sikap, konsep diri, nilai (value), kepercayaan diri, keterampilan berkomunikasi, dan lain-lain.

Dalam dunia kerja, sumber daya manusia (SDM) yang kompeten adalah mereka yang tidak hanya memiliki hard skills saja tetapi juga piawai dalam aspek soft skills-nya. Pendidikan soft skills menjadi kebutuhan penting dalam dunia pendidikan dan dunia kerja.

Konsep tentang soft skillss sebenarnya merupakan pengembangan dari konsep yang selama ini dikenal dengan istilah kecerdasan emosional (emotional intelligence). Soft skills diartikan sebagai kemampuan di luar kemampuan teknis dan akademis, yang lebih mengutamakan kemampuan intra dan interpersonal.

Secara garis besar soft skills dapat digolongkan ke dalam dua kategori : intrapersonal dan interpersonal skills. Intrapersonal skills mencakup : self awareness (self confident, self assessment, trait \& preference, emotional awareness) dan self skills ( improvement, self control, trust, worthiness, time/source management, proactivity, conscience). Sedangkan interpersonal skills mencakup social awareness (political awareness, developing others, leveraging diversity, service orientation, empathy dan social skills (leadership,influence, communication, conflict management, cooperation, team work, synergy). (Hikmaturokhman, 2016)

Soft skills mencakup keterampilan berkomunikasi secara efektif. Orang yang kompeten dalam berkomunikasi adalah orang yang komunikasinya efektif (Turistiati, 2016). Selain keterampilan komunikasi efektif, soft skills mencakup:

- kejujuran

- kemampuan berpikir dan bersikap terbuka

- kemampuan menghormati orang lain

- kemampuan mengelola waktu

- kemampuan berfikir kritis dan kreatif

- kemampuan beradaptasi

Semakin kita handal dalam mengelola soft skills akan semakin tinggi potensi keberhasilan kita dalam memperoleh pekerjaan dan berkarir. Pekerjaan kita akan melibatkan banyak orang dengan banyak kompetensi, sehingga semakin handal seseorang dalam berhubungan baik dengan orang lain, semakin besar kesempatan orang tersebut meraih kemajuan karir.

Pada proses recruitment pegawai, kompetensi teknis dan akademis (hard skills) lebih mudah diseleksi. Kompetensi ini dapat langsung dilihat pada daftar riwayat hidup, pengalaman kerja, indeks prestasi dan ketrampilan yang dikuasai. Sedangkan untuk soft skills biasanya dievaluasi oleh psikolog melalui psikotes dan wawancara mendalam baik oleh psikolog sendiri maupun bagian 
HRD. Interpretasi hasil psikotes, meskipun tidak dijamin $100 \%$ benar namun sangat membantu perusahaan dalam menempatkan 'the right person in the right place'.

Soft skills dapat juga diamati ketika individu atau seorang calon pegawai berkomunikasi, menunjukkan sikapnya (sopan santun tidaknya), secara non-verbal seperti ekspresi wajah (senyum atau cemberut), gesture atau gerak-gerik tubuh, cara duduk dan lain-lain.

Para ahli Sumber Daya Manusia percaya bahwa bila ada dua orang dengan bekal hard skills yang hampir sama, maka yang akan menang dan sukses di masa depan adalah dia yang memiliki soft skills lebih baik. Mereka adalah benar-benar sumber daya manusia unggul, yang tidak hanya semata memiliki hard skills baik tetapi juga didukung oleh soft skills yang tangguh.

Umumnya kelemahan dibidang soft skills berupa karakter yang melekat pada diri seseorang. Butuh usaha keras untuk mengubahnya. Namun demikian soft skills bukan sesuatu yang stagnan. Kemampuan ini bisa diasah dan ditingkatkan seiring dengan pengalaman kerja. Ada banyak cara meningkatkan soft skills, salah satunya melalui learning by doing. Selain itu soft skills juga dapat diasah dan ditingkatkan dengan cara mengikuti pelatihan tentang soft skills

\subsection{Membuat Curriculum Vitae (CV)}

Fasilitator menjelaskan bagaimana membuat Curriculum Vitae. Membuat riwayat hidup yang biasa dikenal dengan curriculum vitae (CV) yang baik dapat menjadi tantangan berat bagi lulusan SMK. Selain konten atau isi CV, desain dan tata letak konten itu perlu menjadi perhatian. Berikut adalah 5 alasan mengapa desain $\mathrm{CV}$ sangat penting seperti yang dilansir oleh totaljobs.com:

- Kesan Pertama

Banyak perusahaan yang benar-benar menilai buku dari sampulnya. Terutama jika perusahaan yang dituju menerima ratusan $\mathrm{CV}$ untuk lowongan yang sama. Untuk itu CV yang dibuat harus terlihat baik dan menonjol ditumpukkan CV lain.

- Menunjukkan profesionalisme

Saat perusahaan menerima CV, secara otomatis mereka akan membuat beberapa keputusan. Meluangkan waktu untuk mendesain CV akan menunjukkan keseriusan dan keprofesionalan si pelamar kerja.

- Mudah dicari

Mendesain CV mampu mempermudah perusahaan mencari CV tersebut di antara tumpukan yang ada.

- Menujukkan pelamar kerja tertata

Sebuah CV yang tidak memiliki desain dan tata letak menunjukkan bahwa orang yang membuatnya tidak mempunyai kemampuan itu dan perhatian yang cukup terhadap detail. Itu adalah adalah dua atribut yang cukup untuk diperhatikan saat menilai pelamar.

- Stand Out

Di antara banyaknya pelamar yang mengirimkan CV, pelamar harus membuat $\mathrm{CV}$ yang menarik dan mencolok sehingga perusahaan tertarik untuk membacanya dibanding yang lain. Dalam CV, pelamar kerja harus menuliskan data diri, juga prestasi atau kemampuan baik hard skills maupun soft skills serta pengalaman apa saja yang sudah dikerjakan terutama pengalaman yang berkaitan dengan pekerjaan atau organisasi. (Jobsmart, 2016)

\subsection{Surat Lamaran Kerja}

Menulis surat lamaran bukanlah tugas yang mudah bagi banyak pencari kerja termasuk lulusan SMK. Surat lamaran kadang-kadang satu-satunya yang dibaca oleh perekrut. Oleh karena itu, surat lamaran harus menjadi bagian yang menggambarkan kemampuan dan prestasi si pelamar kerja. Selain itu surat lamaran harus menggambarkan bagaimana pelamar dapat menjadi pilihan terbaik bagi perusahaan dan pelamar memiliki kualifikasi yang mereka cari.

Para peserta diberi kesempatan untuk membuat surat lamaran yang ditujukan pada suatu perusahaan. Para fasilitator kemudian mengambil beberapa contoh surat lamaran yang dibuat dan dibahas di depan para peserta. Peserta diminta memberikan komentar terhadap surat lamaran yang 
dibacakan oleh fasilitator. Fasilitator memberikan penjelasan, saran, dan tips membuat surat lamaran.

\subsection{Komunikasi dalam Wawancara Kerja}

Fasilitator menjelaskan bagaimana mempersiapan dan mengadakan simulasi singkat mengenai wawancara kerja. Komunikasi dalam konteks wawancara kerja merupakan salah satu cara yang sangat penting bagi suatu perusahaan dalam menyaring jumlah pelamar yang ada. Kegiatan wawancara kerja ini adalah bagian dari rangkaian kegiatan dalam perekrutan karyawan.

Pada proses wawancara kerja, pelamar kerja harus mempersiapkan diri sedemikian rupa terutama dalam hal kemampuan verbal dan non-verbal. Biasanya aspek yang akan mendapatkan perhatian pada saat wawancara adalah aspek kepribadian (personality aspect), yang meliputi :

- Penampilan secara fisik, pakaian yang dikenakan

- Gerak-gerik dan sopan santun

- Ekspresi wajah

- Nada suara

- Kemampuan berkomunikasi

- Rasa percaya diri

- Sikap terhadap pekerjaan

- Inisiatif

- Dll.(Dian, 2016)

Dengan memperhatikan berbagai karakter di atas, pewawancara akan mendapatkan gambaran mengenai calon yang akan terpilih. Wawancara tahap awal sering disebut juga dengan wawancara pendahuluan. Pada tahap ini, wawancara yang dilakukan didasarkan pada lamaran atau CV yang dibuat pelamar. Hal ini untuk memastikan kesesuaian antara kualifikasi yang dimiliki oleh pelamar dengan syarat yang diajukan untuk mengisi suatu posisi jabatan.

Bagi seorang pelamar, pada saat wawancara berlangsung hendaknya memberikan keterangan secara, jelas, singkat, padat dan tidak berbelit-belit. Jangan sesekali memberikan jawaban pertanyaan diluar dari pertanyaan yang diajukan.

Setelah wawancara pendahuluan dilanjutkan dengan wawancara tahap selanjutmya yaitu wawancara seleksi. Dalam wawancara ini biasanya orang yang diwawancarai (calon pelamar) akan ditanya bernagai hal mengenai latar belakang yang mencakup kualifikasi, pengalaman kerja, pelatihan dan semangat kerja yang secara umum untuk mengetahui informasi mengenai calon pelamar yang nantinya akan ditempatkan pada posisi tertentu.

\subsection{Persiapan Wawancara}

Fasilitator memberikan tips bagaimana menghadapi persiapan wawancara kerja. Agar proses wawancara kerja berhasil ada beberap hal yang harus diperhatikan/dipersiapkan antara lain :

- Datang tepat waktu

- Bersikap yakin (optimis)

- Siapkan sertifikat, serta surat penghargaan

- Berpakaian rapi dan sopan

- Bersikap tenang

- Ketuk pintu sebelum memasuki ruangan

- Tersenyum

- Tunggu sampai dipersilahkan duduk

- Ingat nama pewawancara dengan benar

- Melakukan eye contact dengan pewawancara jika berbicara

- Tunjukkan kemampuan diri

- Perhatikan setiap pertanyaan yang diajukan

- Berbicara dengan jelas

- Atur nada suara dan intonasi 
- Tunjukkan minat dan kesungguhan

- Bersikap jujur dan terbuka

Selain melakukan hal-hal tersebut di atas, ada beberapa hal-hal lain yang perlu dihindari dalam suatu wawancara yaitu :

- Terlambat datang

- Terlihat kesal karena menunggu

- Datang Tanpa Persiapan

- Berpenampilan berlebihan

- Membawa tas belanja atau sejenisnya

- Mengajak teman atau keluarga

- Duduk sebelum dipersilahkan

- Meletakkan tas di meja wawancara

- Membungkuk atau menundukkan kepala

- Bertopang dagu

- Melipat tangan di dada

- Merokok atau makan saat wawancara

- Membuka percakapan

- Memotong kalimat pewawancara

- Melebih-lebihkan diri

- Mendikte pewawancara/perusahaan

- Membual

- Mengkritik diri sendiri

- Mengkritik/menjelekkan atasan tempat bekerja

- Memberikan informasi yang tidak relevan

- Bertanya hal-hal yang tidak berguna (basa basi)

- Emosional

- Membuka rahasia perusahaan yang lama

- Tidak sabar. (Alfian, 2013)

Fasilitator menjelaskan semua materi dengan interaktif dan menarik sehingga para peserta tidak merasa jenuh dan digurui. Para peserta diberik kesempatan untuk melakukan latihan wawancara dengan fasilitator sebagai pewawancara.

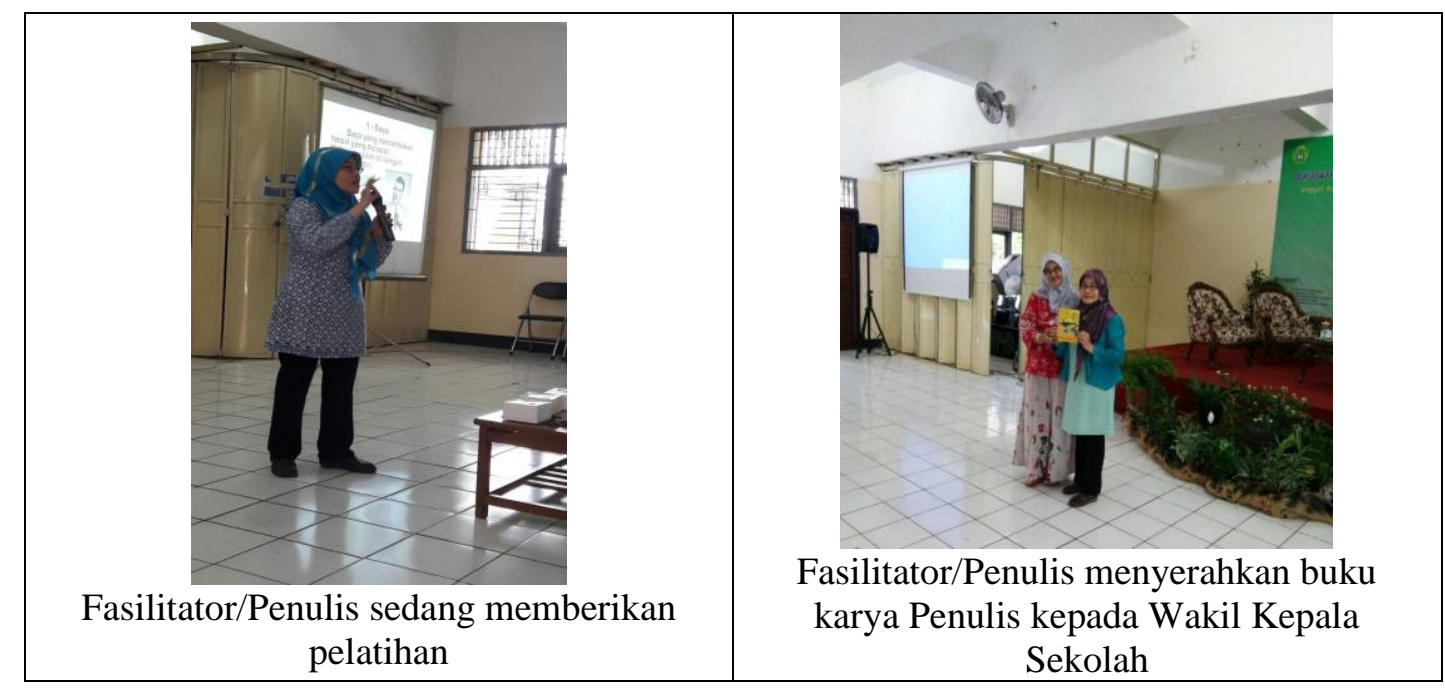




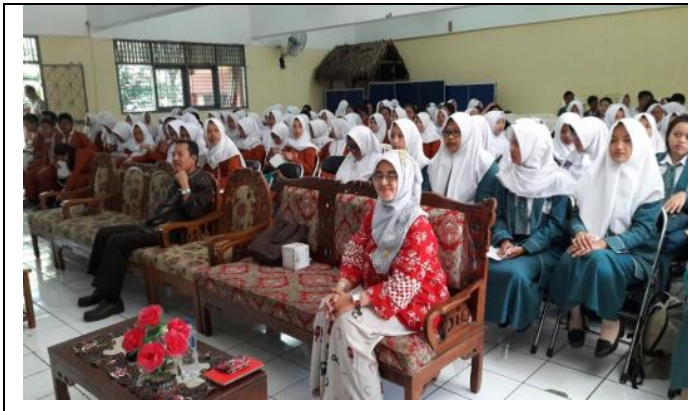

Kepala Sekolah dan Wakil Kepala Sekolah sedang menyimpak pelatihan

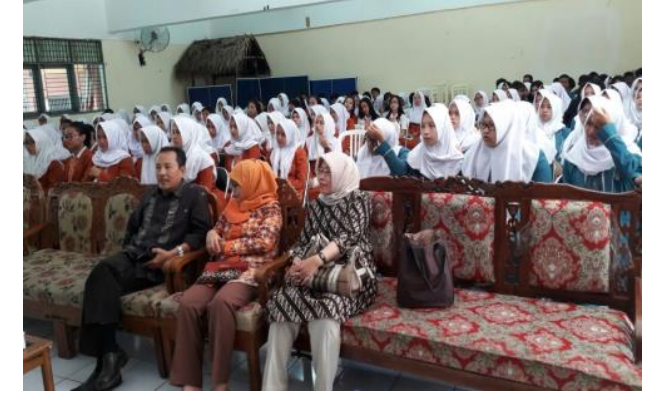

Para guru dan peserta pelatihan ikut menghadiri pelatihan

Foto-Foto Kegiatan Pelatihan Soft Skill

\section{SIMPULAN DAN SARAN}

Acara pelatihan dan pendampingan persiapan kerja ini berlangsung dengan lancar. Para peserta secara interaktif bertanya pada fasilitator dan antusias mengikuti role play wawancara kerja. Selain role play fasilitator memberikan kesempatan kepada peserta untuk membuat $\mathrm{CV}$ dan lamaran kerja. Fasilitator memberikan contoh lowongan kerja dengan beberapa posisi yang akan dilamar oleh pencari kerja. Fasilitator kemudian membahas beberapa CV dan surat lamaran kerja untuk dibahas bersama.

Banyak peserta yang menyampaikan bahwa acara ini waktunya kurang. Selain itu dalam suatu batch orangnya terlalu banyak. Pada kesempatan lain, untuk acara kegiatan serupa waktunya ditambah misalnya sehari penuh dan pesertanya dikurangi misal hanya 25 orang per kelompok sehingga hasilnya lebih efektif.

\section{DAFTAR PUSTAKA}

Alfian, N. (2013). Komunikasi Wawancara Kerja. Retrieved from www.fungsiumum.blogspot.co.id/2013/06/komunikasi-wawancara-kerja

Carey, John; Churces, R. (2010). Neuro-Linguistic Programming and Learning: Teacher Case Studies on the Impact of NLP in Education. Research Paper. Retrieved from https://files.eric.ed.gov/fulltext/ED508368.pdf

Dian, F. (2016) Komunikasi Wawancara Kerja. Retrieved from www.blogspot.co.id/2013/06/komunikasi-wawancara-kerja

Hikmaturokhman, A. (2016). Pentingnya Soft Skill. Retrieved from http://sinauonline.50webs.com/Pentingnya Softskill.html

Jobsmart. (2016). 5 Alasan Mengapa Curriculum Vitae itu Penting Saat Melamar Pekerjaan. Retrieved from http://blog.jobsmart.co.id/2016/02/24/5)

Millrood, R. (2004). The Role of NLP in Teachers' Classroom Discourse. ELT Journal, 58(1), 28 37.

Nikolay, H. (2014). Licensed Practitioner of Neuro Linguistic Programming. Jakarta: Inspirasi Indonesia.

Sun, S. H. Dynamic Nuero Linguistic Programming Synergistic (2016). Retrieved from https://www.quora.com/What-are-the-key-differences-between-NLP-and-NAC,

Turistiati, AT. (2016). Intercultural Communication Competence: Its Importance to Adaptation Strategy towards People With Different Cultural Background. Ijtimā'iyya: Journal of Muslim Society Research, 1(1), 63-78. Retrieved from https://doi.org/https://doi.org/10.24090/jmsr.v1i1.927

Undang-Undang Republik Indonesia No. 20 Tahun 2003 tentang Sistem Pendidikan Nasional. (2016). Retrieved July 16, 2018, from http://kelembagaan.ristekdikti.go.id/wpcontent/uploads/2016/08/UU_no_20_th_2003.pdf 